\title{
Assessing the performance of earth building materials: a review of recent developments
}

\author{
Antonin Fabbri ${ }^{*}$, Jean-Claude Morel ${ }^{b}$, Domenico Gallipoli ${ }^{\mathrm{c}}$ \\ a LTDS, UMR 5513 CNRS, ENTPE, Université de Lyon, 69100 Vaulx-en-Velin, France \\ ${ }^{\mathrm{b}}$ Research Centre for the Built and Natural Environment, Faculty of Engineering, Environment \& Computing, Coventry University, Coventry, UK \\ ${ }^{\mathrm{C}}$ Fédération IPRA, Laboratoire SIAME, Université de Pau et des Pays de l'Adour, 64600 Anglet, France
}

\begin{abstract}
After being almost abandoned in Europe at the end of the Second World War, raw earth is currently regaining the interest of civil engineers and architects worldwide. Raw earth (unfired earth) displays very interesting thermo-hygro-mechanical properties, which can contribute to the reduction of the environmental impact of buildings not only during construction but also during service life. Nevertheless, one of the main reasons preventing dissemination of raw earth into mainstream construction practice is the lack of commonly agreed protocols for assessing engineering performance. In this context, the RILEM Technical Committee 274-TCE is critically examining current experimental procedures to propose appropriate testing methods that could be adopted as standards. The present paper summarizes the main challenges faced by the committee and describes some of the existing procedures for measuring the engineering properties of earth materials. The main issue identified by the committee is that laboratory protocols do not accurately reproduce field conditions. The representativeness of laboratory samples is also questionable due, for example, to different degrees of material homogeneity with respect to the field. Finally, the paper identifies some possible routes to reduce the discrepancies between laboratory testing and field conditions in relation to the thermo-hygro-mechanical characterization of earth materials.
\end{abstract}

Keywords: Rammed earth; Adobe; Cob; CEB; Hygrothermal performance; Hydromechanical performance; Durability

\section{Introduction}

Humans have used raw earth in various forms during millennia for the construction of dwellings. After the Second World War, however, the use of raw earth was almost abandoned in industrialised countries due to the diffusion of concrete and steel. This tendency has been inverted only in recent decades when earth building has started to regain the interest of architects, engineers and policy makers because of its ecological prerogatives. Earth is an abundant and recyclable material, which generates little construction waste. Earth is also less energy-demanding than conventional building materials such as, for example, concrete and steel $[1,2]$.

Nevertheless, one of the main reasons preventing the dissemination of raw earth into mainstream construction practice is the absence of internationally acknowledged standards for assessing the thermo-hygro-mechanical performance and the durability of the material. A good understanding of these two aspects requires taking into account the large variability of earth materials which is mainly due to: a) the different geological characteristics of the sites from where the earth is sourced and b) the different construction techniques, which can vary depending on soil types and manufacturing tools.

Among the different construction techniques, the most common ones are adobe, cob and rammed earth [3]. Adobe bricks are manufactured from wet earth which is moulded into a frame and then dried to the sun. Cob consists instead of a monolithic wet earthen mixture, which is ladled in courses onto a foundation. Finally, rammed earth is the product of compacting consecutive soil layers (ideally at the optimum water content to maximise density) within a formwork by using a manual or pneumatic rammer. A recent variation of rammed earth consists in the fabrication of compressed earth blocks that are subsequently assembled in the form masonry structures. The above descriptions are however rather general and manufacturing protocols can strongly vary in function of climate, location and skills. Other construction elements are also gaining popularity including extruded raw earth bricks and prefabricated rammed earth panels.

* Corresponding author: Antonin Fabbri, E-mail: antonin.fabbri@entpe.fr 
Besides the above differences, a number of similarities exist between different earth building methods. Firstly, all earth walls are relatively thick ( 30 to $50 \mathrm{~cm}$ ) and are separated from the underlying ground by a foundation that prevents capillary rise. Moreover, all earth materials are composed of distinct soil fractions including silts, sands and possibly gravels which are bound together by a clayey matrix that provides cohesion. The connections between these different constituents are not perfect and small voids are embedded within the material forming a porous network that enables gas or liquid flow. Raw earth is generally classified as a porous material with relatively low resistance to vapour and water transfer. The high water affinity of clays, and possibly embedded fibres, also facilitates the capillary condensation and adsorption of water inside the porous network. This combination of moisture transport, condensation and sorption mechanisms confers a marked hygroscopic nature to earth materials and a great ability to regulate indoor relative humidity. Furthermore, the exchanges of latent heat that occur during the condensation/evaporation and adsorption/desorption of pore water can strongly enhance the thermal inertia of the material.

The high hygroscopicity of raw earth has also an impact on the mechanical properties as a consequence of the interaction between the pore water and the clay fraction. This interaction can result in swelling or shrinkage $[4,5]$ and can cause the reduction of strength and stiffness. A common way to reduce the adverse effect of water on mechanical behaviour and therefore to enhance the durability of earth materials consists in the addition of hydraulic stabilisers such as cement or lime [6], which however increases the environmental impact [7]. Recent research has therefore focused on the development of alternative binders, from cow dung [8] to geo-polymers [9], with lower energy/carbon footprints than conventional hydraulic ones. Stabilisers may also generate adverse effects on the behaviour of raw earth when exposed to fire, frostthaw and wetting-drying cycles due to a modification of the binding fraction and the consequent change of the porous structure.

Some of the most important open questions about the design of effective earth building materials relate to: a) the optimal characteristics of earth mixtures and b) the assessment of material performance in relation to sustainability, strength, seismic resistance, thermal behaviour, moisture buffering capacity and durability.

Questions about the optimal characteristics of earth mixtures have been partly answered by current recommendations, guidelines and standards. For example, the BS1377 standard defines an admissible range of particle grading for rammed earth construction while other research works, e.g. [10], recommend proportions of clay (15-30\%), silt (10-30\%) and sand (50-75\%) for adobe blocks. In general, the clay content should be sufficiently high to ensure acceptable levels of stiffness and strength while the expansive fraction should remain below $50 \%$ of the total clay content to avoid cracking. The analysis of existing buildings also indicates that particle size distribution cannot be used as the only parameter to discriminate between earth materials [11-13] and that no objective rule currently exist to assess suitability for building based solely on granular properties.

Questions about the assessment of material performance are more difficult to answer given the diversity of test procedures, which are often tailored to specific materials or external actions. This difficulty has recently led to the establishment of the RILEM technical committee TCE 274 which has the mission of defining accurate, repeatable and reproducible performance-oriented testing protocols that could, in the future, be adopted as international standards. The results of this work will be presented in upcoming publications while this paper intends simply to provide a summary of the main challenges faced by the committee together with a brief description of existing procedures for measuring the engineering properties of earth materials.

The paper is divided in three parts: the first part deals with the study of hygroscopic and thermal performance, the second part is dedicated to the assessment of mechanical behavior and the third part analyse the main factors that affect durability.

\section{Assessment of hygrothermal performance}

\subsection{Main hygrothermal material parameters}

In civil engineering, the hygroscopicity of a material is defined as its ability to act as a passive humidity regulation system. For that purpose, the velocity at which water molecules are adsorbed is at least as important as the total amount of water molecules that can be adsorbed. The term "hygrothermal" is commonly used to denote the couplings between mass transfers of water phases, including their phase changes, and heat transfer. These two concepts are thus linked together, and a material with good moisture buffering capacities will also show good hygrothermal properties.

The main equations of hygrothermal couplings are nowadays quite well known by the scientific community, and their detailed and comprehensive descriptions are provided in many papers, including [14] and [15]. Briefly, if local equilibrium is assumed, the conservation equations that drive the hygrothermal couplings can restricted to a system of three partial differential equations, two of them based on mass balance equations, and one on the heat balance. These relations are driven by three main groups of parameters. The first one is the thermal parameters, which are identified as the thermal conductivity, denoted by $\lambda$, and the heat capacity at constant pressure, denoted by $C_{p}$. For convenient purpose, these parameters can be replaced by the thermal diffusivity $\left(a=\lambda / C_{p}\right)$ and effusivity $\left(e=\sqrt{\lambda C_{p}}\right)$. The second one is the mass transport properties, that are the vapour diffusion coefficient, $\delta_{p}$ and the permeability to liquid and gas. Finally, the last one would be the sorption-desorption curves, which will give the water content $(w)$ of the material in function the relative humidity $(\varphi)$ for a given temperature $(T)$, and that allows to determine the water storage capacity, $\xi=\partial w / \partial \varphi$, and eventually the evolution of water content with temperature at constant relative humidity (i.e. $\chi=$ $\partial w / \partial T)$. The measurement of all these parameters is not 
trivial, since they can be strongly influenced by both temperature and relative humidity.

\subsection{Measurement of material properties}

\subsubsection{Thermal properties}

The values of the dry thermal conductivity of earthen materials reported in literature is quite scattered (values between $0.2 \mathrm{~W} / \mathrm{m} / \mathrm{K}$ and $2 \mathrm{~W} / \mathrm{m} / \mathrm{K}$ were measured), and no clear tendency can be found with dry density [16-27]. Similarly, the measured increment of thermal conductivity with water content seems strongly dependant on the tested material and on the test protocol. One explanation of these differences may the variability of the material, but another one may be the large number of testing methods. The most common ones are the "Guarded Hot Plate", which is a steadystate method recognized by a number of international standards (for example, [28], [29] and [30]) to measure the thermal conductivity and, the transients methods, like "Needle Probe", "Line Source" or "Hot Wire" described in the international standards [31] and [32] and the "Plane Source" or "Hot Disk" described in the international standard [33]. These latter can be used to estimate both the thermal conductivity and the heat capacity. However, to date, no study clearly indicates the impact of these methods on the obtained results for earthen materials.

Finally, the "Differential Scanning Calorimetry" is one of the most common techniques to measure the heat capacity of materials [34-36], but fewer studies have been realised with this apparatus on earthen materials. One of them have been realised in the $80 \mathrm{~s}$ by [17]. It showed values in the range of $1500 \mathrm{~kJ} / \mathrm{m}^{3} / \mathrm{K}$ for dry earth, and a linear variation with water content.

\subsubsection{Vapour permeability}

Water vapour permeability is commonly measured according to the "wet cup" or "dry cup" methods using the standard EN ISO 12572. Basically, the experimental protocol used for these two tests consists in placing the sample on top of a cup whose relative humidity is controlled by a saline solution. For the wet cup, a potassium chloride solution is commonly used, leading to a relative humidity level of $85 \%$ at $23^{\circ} \mathrm{C}$. For the dry cup, silica gel may be used, but potassium acetate solution ( $\mathrm{RH}$ level, $25 \%$ at $23^{\circ} \mathrm{C}$ ) was found to provides better stability of relative within the dry cup [37]. To seal the samples to the cup, a vapour-tight aluminium tape is often used, because it does not adsorb a significant quantity of moisture itself [38]. The assemble is then put in a chamber at controlled relative humidity and temperature. The difference in vapour pressure between the cup and the chamber, denoted by $\Delta p_{v}$ and equal to the difference in relative humidity multiplied by the vapour pressure at saturation (equal to $28 \mathrm{mbar}$ at $23^{\circ} \mathrm{C}$ ), creates a flow of vapour through the sample.

The test analysis consists in matching the mass variation of the cup assembly (wet or dry) denoted by $G$ and the mass flow of vapour through the sample, which is equal, at first order, to $A \delta_{p} \Delta p_{v}^{A} / d$, where $d$ is the thickness of the sample,
$A$ its cross section and $\Delta p_{v}^{A}$ is the difference in partial pressure of vapour between the two faces of the samples. $\Delta p_{v}^{A}$ is not rigorously equal to $\Delta p_{v}$ due to diffusion within the cup and/or convection phenomena at the sample surfaces. To take that into account, the EN ISO-12572 standard provides a correction assuming that the transport of vapour within the cup is only made by diffusion (no convection). However, many studies had investigated that the water vapour permeability obtained from such experiment, even after this correction, show a significant dependency on the sample thickness [37], [39]. To avoid this problem, and to determine the "real" water vapour permeability it is necessary to do a second correction which consider the effect of film moisture resistances at sample surfaces. The general expression of the vapour diffusion coefficient then becomes:

$$
\delta_{p}=\frac{G d}{A \Delta p_{v}-\frac{G}{\beta}}
$$

where $\beta$ stands for the cumulate effect of the surface films and air layer resistances. The empirical estimation of this parameter can be done from the analysis of the variation of $1 / G$ with the sample thickness while assuming that only the surface films and air layer resistances would remain if the thickness of the sample tend to zero $[37,40]$.

The measure of $\delta_{p}$ is commonly made at $23^{\circ} \mathrm{C}$ and 1 bar. However, its value varies with temperature and gas pressure. Classically, this variation is assumed to be similar than the one of $\delta_{a}$. This assumption seems to be validated by most of the construction materials, since the ratio between $\delta_{a}(T)$ and $\delta_{p}(T)$, namely the vapour resistance factor denoted by $\mu$, was found to be independent of temperature on materials such as compacted earth [41], hemp concrete [42], aerated concrete, calcium silicate board, and ceramic bricks [43].

Let us finally underline that these previous developments where made under the assumption that no vapour advection and no liquid water transport occur within the material and that $\delta_{p}$ do not vary with water content. It is quite clear that these assumptions are not true, but the assessment of their impact still need to be done.

\subsubsection{Liquid water and air permeability}

The permeability characterizes the ability of a fluid mass to move through the porosity of a material. It is classically written as the product between the intrinsic permeability and the relative permeability coefficient.

The intrinsic permeability depends on the geometry of the porous network, and it should not depend on the fluid which filled the porous material. It is however not practically the case. Indeed, a difference up to one order of magnitude can be observed between gas and liquid water intrinsic permeability. It is commonly attributed to the differences between water/solid and gas/solid interactions, and slip effects during gas permeability measurement [44]. However, most of the studies on earthen materials have only focused on liquid water permeability.

The relative permeability is a coefficient between 0 and 1 that depends on the volumetric proportion of the pore space occupied by adsorbed and/or condensed water molecules. 
The estimation of this latter is particularly complex, in particular for low saturation ratio, and no clear studies have been made yet on its estimation for earthen materials.

A classic way to measure the liquid water permeability of saturated soils is to use an oedometer with the variable hydraulic load method, which is notably described in the French standard NF X 30-442. This method is however almost never used for earthen materials, for which water absorption experiments are preferred. One of them, which is described in the British standard BS 3921, consists in measuring the Initial Rate of Suction (IRS) by immerging a sample in water to a depth of $3 \mathrm{~mm}$ during $1 \mathrm{~min}$. For its part, the European standard EN 1015-18, prescribe the use of the A-Value (or its volume counterpart the sorptivity), which is the total amount of water absorbed (in $\mathrm{kg}$ ) per the surface in contact with water (in square meters) and per the square root of the immersion time (in seconds). Due to the lack of accuracy of the IRS measurements, the A-Value is commonly preferred. But, even for this latter, significant variability of experimental protocol exists. In particular, the analysis of the studies [45], [46], [47], [48] and [49] underlines significant differences on the sample geometry, its conditioning and the weighting frequency. Finally, absorption tests do not directly give the permeability of the material, and if some relations exist to link the A-Value to water diffusion and/or permeability coefficients, like the one proposed by [50], their accuracy for earthen material have not yet been proven.

\subsubsection{Sorption-desorption curves}

Several methods exist to estimate the isothermal sorptiondesorption curves [51], but the two most widely used are the desiccator and dynamic gravimetric vapour sorption methods.

The experimental protocol of the desiccator method is defined in the international standard ISO 12751. The sorption stage consists in successively putting a previously dried sample in several environments of increasing $\mathrm{RH}$ and constant temperature. The sample is periodically weighed and it stays within a given environment until mass constant. The desorption stage consists in successively putting a sample previously equilibrated at $95 \% \mathrm{RH}$ (at least) in several environments of decreasing $\mathrm{RH}$ until mass constant and at constant temperature. The $\mathrm{RH}$ of the environments is fixed by equilibrium with saturated saline solutions.

The dynamic gravimetric sorption method, commonly called the DVS (dynamic vapour sorption) method, consists in measuring uptake and loss of moisture by flowing a carrier gas at a specified RH (or partial pressure) over a small sample (from several milligrams to several grams depending on the device used) suspended from the weighing mechanism of an ultrasensitive recording microbalance. Variations in the gas's $\mathrm{RH}$ are automatically calculated by the device when the target condition in mass stability is reached. A sorption-desorption loop can thus be made in approximatively 1-2 weeks for earthen materials, while a period of 2-4 months is necessary if the desiccator method is used. On the other hand, the desiccator method can test several specimens at the same time, and it is the only way to test specimens with high levels of heterogeneity like earth-fibres mixtures. A good consistency was observed by [52] with these two methods on compacted earth samples and earth plasters if the same method is used to estimate the dry mass.

An important topic related to sorption and desorption curves is the hysteresis (that is the non-reversibility) on the water content which is commonly observed when the material is submitted to cycles of $\mathrm{RH}$. This phenomenon is quite common and has been widely studied by many authors for a large variety of materials, $[53,54]$. But no clear evidence of the necessity to use such level of complexity to properly model the hygrothermal behaviour of earthen materials has been proofed yet. In particular, as it is shown in Fig.1 for an earth plaster, if moderate cycles of relative humidity are performed, the hysteresis becomes almost null.

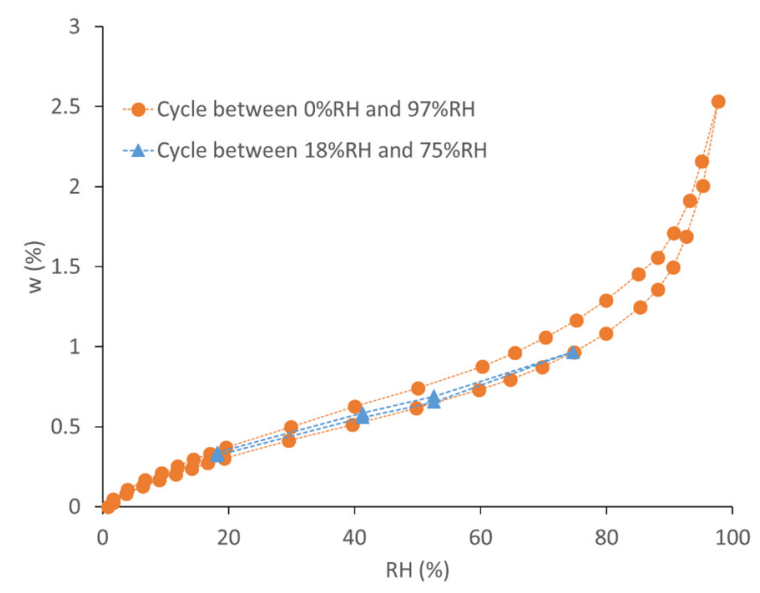

Figure 1. Influence of the amplitude of the sorption-desorption cycle on its hysteresis. The test is made with the DVS method on the earth plaster referenced as P1 in [52].

Finally, the sorption-desorption isotherms are known to be impacted by temperature. This effect was studied in [52] on compacted earth and earth plasters. It led to the conclusion that it can be neglected if the range of temperature variation remains limited (lower than $40^{\circ} \mathrm{C}$ ).

\subsubsection{Assessment of the hygroscopic buffering potential}

Two main tests which are used to estimate the hygroscopic potential of earthen materials are the maximal absorption value and the moisture buffering value (MBV).

The maximal adsorption value is defined in the DIN standard. It consists in the measurement of the mass uptake after $12 \mathrm{~h}$ at $80 \% \mathrm{RH}$ of samples initially stabilized at $50 \% \mathrm{RH}$.

The protocol of the MBV test has been originally defined within the framework of the NordTest project [55]. It indicates the amount of moisture transported in or out of a sample during isothermal daily cycles. The most used cycle in literature data consists in 8-h time steps at 75\% RH and 16-h time steps at $33 \% \mathrm{RH}$. The sample tested is isolated on all its sides except one, and the $\mathrm{MBV}$, in $\mathrm{kg} / \mathrm{m}^{2} / \% \mathrm{RH}$, is calculated as the mass variation during the cycle per unit of surface area 
of the open surface divided by the difference between the lower and the higher relative humidity of the cycle.

Reviews on the buffering capacity of hygroscopic building materials have been recently published, either using maximal absorption value [56] or the MBV test [57]. The studies both underlined the good to excellent moisture buffering potential of earthen materials.

Finally, let us underline that all the existing tests on hygroscopic materials only focus on the adsorption of water, while it is not the only gaseous component which can be adsorbed at the pores surfaces of earthen material. Indoor pollutants are mainly gaseous or solubilised compounds: $\mathrm{CO}_{2}$, NOx, volatile organic compounds (VOCs), formaldehyde, phthalates, polycyclic aromatic hydrocarbons (PAHs), tetrachloroethylene [58]. The experimental methods to evaluate the contribution of earthen materials to IAQ are typical developed in the analytic chemistry field. The retention capacity could be evaluated on samples exposed to the different sources of pollutants (alone or in mixture) through the characterisation of kinetics and adsorption isotherms (chromatography), retention factor, diffusion and emission. Furthermore, as concentration of pollutants depend on the temperature, these characteristics have to be considered relating to the thermal properties of earthen materials.

\section{Assessment of the hydro-mechanical performance}

The previous section underlines how earth is sensitive to water and how the coupling with the thermal behaviour is crucial. Similarly, water has a high impact on the mechanical

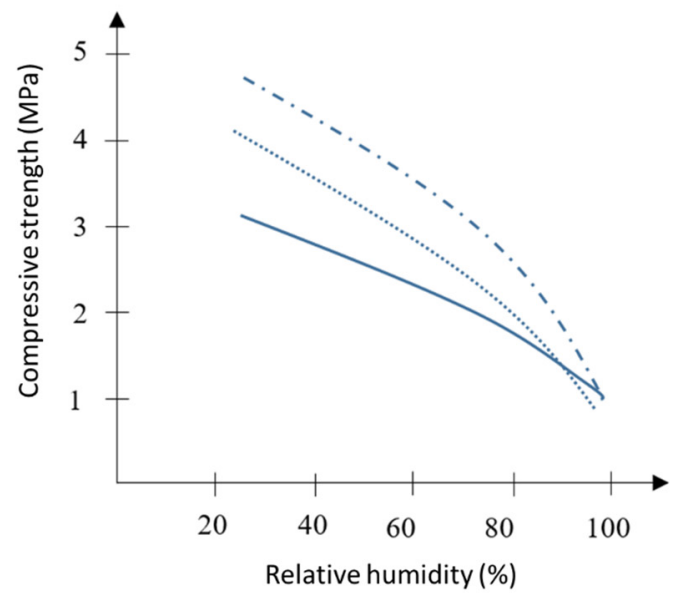

behaviour of the earth-based materials. See for example the impact of relative humidity in Fig. 2 (adapted from [11-13]). The same kind of relation have been observed between compacted earth strength and water content ([59-62]).

Therefore, all the mechanical tests on earth must be performed with a procedure to manage water (liquid or vapour). Usually tests are performed on "dry specimens" which has two main drawbacks. Indeed, the definition of dry state varies following authors. They all proceed by putting the specimens in an oven until the stabilization of their weight. However, the set temperatures of the oven vary between $40^{\circ}$ $\mathrm{C}$ to $105^{\circ} \mathrm{C}$. Heating the sample at $105^{\circ} \mathrm{C}$ will modify its behaviour and will drive away the material strength from the actual value in a building. On the other hand, too low temperatures would not give reproducible results, since they could be impacted by the humidity of the room in which the oven is. Therefore, the best way would be to test for a given range of $\mathrm{RH}$ and not in the "dry state". In that case, the test must be as short as possible not to allow a sharp change in the $\mathrm{RH}$ inside the sample. Ideally, the testing device should be in a monitored environment with a $\mathrm{RH}$ and a temperature control.

In this paper, we are deliberately considering specimens manufactured in laboratory. So that we will address the process of manufacturing the specimen in order to be representative to the actual materials on site. We will not address the tests on specimens issued from actual material in use, for example, Compressed Earth Blocks (CEB) or rammed earth samples cut from existing walls. There are a number of references $[6,45,60,63,64]$ dealing with this and no consensus is emerging from this, mainly due the variation of the shapes of the samples.

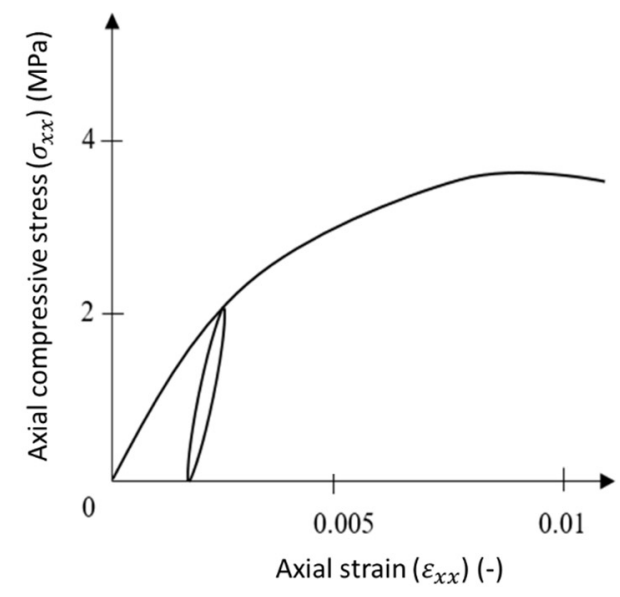

Figure 2. (a) Sharp decrease of compressive strength with Relative Humidity for 3 different earths used in vernacular rammed earth architecture; (b) Typical stress-strain behaviour of earth during a compression test on cylindrical specimen of aspect ratio of 2 , vertical axis $x$, with one cycle at $2 \mathrm{MPa}$ with strain measured locally; from [11-13].

\subsection{Procedure to manufacture specimens for laboratory testing}

Earth, before being a construction material is a soil, either compacted or moulded. It can be easily manufactured in a classical laboratory of civil engineering. However, it is important to manufacture specimens that are representative of the actual material used in the building. To achieve this aim, several studies (e.g. [65-67]) have pointed out that it is necessary to take into account two key parameters. The first 
one is the manufacture water content (or $\mathrm{RH}$, since they are linked together, see Fig. 1). The second is the dry density of the specimen. In conclusion, the sample manufactured in the laboratory should have the same dry density as the actual material on site, and should have approximately the same manufacture water content. These studies tend to proof that it not necessary to know exactly the in situ energy of compaction, or the in situ moulding process if the dry density is equal in laboratory and in situ. The shape of the specimen will be defined following the performance to be tested.

\subsection{Main material mechanical parameters}

Before defining the mechanical parameters, it is crucial to define the framework in which the mechanical performances of earth are considered. Since early 1990s [68], the most appropriate approach seems to be the one developed for unsaturated soils. However, this approach deals with a certain degree of complexity and for example requires performing triaxial tests to determine the hydro-mechanical behaviour. In geotechnical engineering, soils are usually confined due to the weight of soils above a given depth, whereas earth walls in a building are not. Moreover, the designers currently need appropriate design parameters to expand the market of earthen construction. Therefore, there is balance to be found. As we are in the early age of engineering design of earthen structures, it is still necessary to oversize such structures in the mechanical point of view and therefore allowing to design with simple mechanical parameters.

\subsection{Measurement of material properties}

\subsubsection{Compressive strength}

This is the main mechanical parameter because usually the architectural design not involve deliberately tensile stresses in earthen materials. The specimens should be tested following the framework of continuum mechanics with a specimen size enabling to have negligible side effects to ensure that the strain and stress tensors are homogeneous within the specimen. In that case, it is possible to get the stress by the force sensors at one end of the specimen and the strain from extensometers clipped on the specimen. The strains are not useful to determine the compressive strength though.

In addition to the dry density and water content issues, a key challenge remaining at this stage, when measuring the compressive strength, is the size of the specimen. As for soil mechanics, a slenderness ratio of 2 would be optimum in terms of friction (confinement from the press platen), in terms of gradient of dry density and in terms of volume enabling to test the full content of earth (including gravels or small stones). As it is underlined by [69], compression tests on samples of smaller slenderness ratio would lead to unrealistic results. However, if the manufacture of samples with a slenderness ratio of two is quite easy for rammed earth or cob, it is more complicated for compacted earth blocks and adobes. To date, if some proposals have emerged, like the superposition of half-blocks bound by a mortar [70] or the indirect estimation from a 3-point bending test [71], no consensus have been reached.

\subsubsection{Stiffness parameters}

During the compression test, it is possible to get accurate strains using local measurement methods. It could be extensometers clipped on the sample or non-contact sensors or using photogrammetry [13]. It is not possible to get accurate data from the displacement sensors of the press due to deformability of interface between the specimen and the press platens [63]. Earth materials may follow the Hooke's law in a very limited domain of small stresses (approximately less than $5 \%$ of the compressive strength). Therefore, the only way to measure an elasticity module is to apply cycles during the compressive tests (Fig. 2b).

\subsubsection{Shear behaviour}

The first attempt to give an accurate rheology of compacted earth was made by Myriam Olivier in 1995 [72]. It was followed by several works (for example $[62,73,74]$ ), which led to the development of law of behaviours of increasing levels of complexities (poro-elasto-plastic, anisotropy of the plastic criterion, damage etc...). Even if these studies are of main interest for the future of earthen constructions and the optimisation of their design, in practice, such level of complexity is not yet considered. Currently, the limits of the shear stresses are commonly given by Mohr-Coulomb criterion, which is defined by two parameters, the cohesion and the friction angle. To measure these parameters, testing procedures from two different origins can be found in literature. The tests primarily designed for brick masonries, namely triplet test [75], push over [76,77] and diagonal compression test (DCT) [78,79], and the tests from geotechnical engineering, namely the direct shear test (DST) also called shear box test $[80,81]$, and the triaxial test $[75,82$ 85]. The analysis of the data reported in literature for rammed earth does not give a clear tendency, whatever the testing protocol considered. Indeed, cohesions between $30 \mathrm{kPa}$ and $600 \mathrm{kPa}$ and friction angles between $35^{\circ}$ and $75^{\circ}$ are found, with no sound correlations with dry density and/or water content. This lack of correlation may be due to the role of the interface between the rammed earth beds, which are classically not considered since the plain shear behaviour is estimated considering the material as homogeneous.

For adobe and CEB masonry, the tests to assess the shear behaviour of the interfaces are similar to the test designed for the baked brick masonry [86-88].

\subsubsection{Tensile strength}

The tensile strength of earth material is commonly estimated through direct traction test [82] or using the Brazilian test [89]. These studies lead to a ratio of approximately 10 , between the tensile and the compressive strength. In consequence, earth is usually considered as a non-tensile material especially for structures with weak joints like rammed earth, or small block masonry (adobe or Compressed Earth Block units). If the design cannot avoid tensile stresses, then it is necessary to reinforce the structure. The reinforcement approach should take into account the specific 
hygrothermal and mechanical behaviour of earth, which would lead to prefer timber to concrete or steel. For adobe and CEB masonry, the tests to assess the tensile strength of the interfaces are similar to the test designed for the brick masonry $[87,88,90,91]$.

\section{Durability of earthen materials}

\subsection{Main environmental agents affecting durability}

Research on the durability of earth buildings has gained significant momentum over the last two decades. The number of Scopus indexed articles containing all three words "durability", "earth" and "buildings" in the title or abstract was less than twenty in the year 2000 but has steadily increased to about two hundred in the year 2018.

The main environmental actions that affect the durability of earth buildings are water, ice, wind, fire, solar radiation and chemical agents. The durability of earth buildings is also affected by their interaction with the biosphere, and in particular, by the actions of insects, burrowing animals and plant roots, though this aspect is outside the scope of the present paper.

Table 1 summarizes the overall impact of water, ice, wind, fire, solar radiation and chemical agents on the durability of earth buildings and provides a brief description of the physical mechanisms through which each of these environmental actions operates. Past research has not focused equally on all six actions of Table 1 but has privileged those with the most adverse impact on the durability of earth buildings worldwide. Therefore, the largest share of research has been devoted to the effect of water or humidity, e.g. [92-95] while fewer studies have considered the effects of ice [96-98], fire [99], wind [100-102], solar radiation [103,104], and chemical agents [105].

Inspection of Table 1 indicates that earth buildings are most vulnerable to the action of water and ice. Water is particularly detrimental for unstabilised earth while ice tends to undermine predominantly stabilised earth. Both actions of water and ice tend to produce a fast advancement of damage, which often impedes the timely detection of deterioration processes and the consequent implementation of countermeasures. Overall, water has a more adverse impact on durability compared to ice mainly because it is ubiquitous while ice only occurs in cold climates. Moreover, the preponderance of earth buildings in areas characterized by temperate climates has so far offered relatively little opportunity to assess vulnerability to frost.

Table 1 also shows that stabilised earth buildings are particularly vulnerable to fire because high temperatures can produce a loss of inter-granular cementation and can therefore rapidly damage stabilised earth materials. Nevertheless, blazes remain exceptional events, which explains the moderate overall impact of this environmental action on the durability of earth buildings.

Throughout their service life, buildings are also exposed to the action of wind and solar radiation in the same way as they are exposed to the action of rainwater. Nevertheless, despite the high likelihood of all these actions, the level of structural vulnerability to wind and solar radiation remains significantly lower compared to water. Wind poses a moderate threat only to unstabilised earth structures that may be sensitive to surface mechanisms such as erosion and abrasion. Similarly, the effect of solar radiation is often limited to an unaesthetic discoloration of photosensitive binders like in the case of polymer-stabilised earth. This change of appearance, however, rarely evolves into a more serious embrittlement of the cementing fraction. Importantly, the damages caused by wind and solar radiation progress rather slowly and can therefore be counteracted by regular maintenance of the building envelope.

Finally, earth buildings exhibit a relatively low vulnerability to chemical agents such as dissolved ions or salts. Vulnerability may become significant only if the earth is stabilised with chemically sensitive binders (e.g. cement) or is reinforced with corrodible materials (e.g. steel), and if specific environmental conditions are present on site. These specific environmental conditions consist in the presence of unusually high concentrations of pore water salts and/or exceptionally high levels of alkalinity/acidity. The progression of the damage caused by chemical agents is normally slow, thus allowing the execution of remedial works if necessary.

The above six environmental actions can undermine the durability of earth structures through physical mechanisms that may be grouped into different classes based on similarities between them. The largest class includes deterioration mechanisms that originate from a loss of intergranular bonding, which in turn produces a reduction of cohesive strength and, hence, material damage. This class of mechanisms is relevant to both unstabilised and stabilised earth but the nature of the inter-granular bond is different in the two cases. In the case of unstabilised earth, the bond is governed by capillarity and is negatively affected by an increase of pore water. Instead, in the case of stabilised earth, the bond is governed by chemistry and is negatively affected by the occurrence of thermo-chemo-mechanical processes. Another relatively large class of deterioration mechanisms is characterized by the occurrence of cracking/spalling of earth walls. This may be caused by either swelling/shrinkage or by the confined expansion of gas (vapour) or solid phases (ice or salts) inside material pores. Finally, a less common class of deterioration mechanisms involves the erosion of the wall surface due to the mechanical impact of meteoric precipitation or wind, especially if carrying suspended particles.

\subsection{Measurement of durability}

There are very few measurements of the durability of full scale earth walls exposed to natural climate over a prolonged period of time. Albeit rare, these measurements are extremely useful as they show the simultaneous effect of different environmental actions, such as those of water, wind and solar radiation. The effect of ice and chemical agents might also be included in field experiments depending on the ambient conditions at the test site. The only action that is 
rather exceptional, and that is therefore typically excluded from field studies, is the action of fire. In reality, the absence of detailed investigations at field scale on the effect of ice, fire and chemical agents is one of the main reasons why the impact of these three actions is still relatively unclear.

In one the few published field experiment [106], the authors measured the erosion of unstabilised and stabilised uncoated rammed earth walls exposed to the wet climate of Grenoble (France) for a period of 20 years. The final erosion depth was about $6.4 \mathrm{~mm}$ for unstabilised walls and about $2 \mathrm{~mm}$ for stabilised walls, which corresponds to annual erosion rates of
$0.32 \mathrm{~mm} /$ year, in the former case, and $0.1 \mathrm{~mm} /$ year, in the latter case. Another field study [107] measured the erosion of an unstabilised uncoated rammed earth wall built on the campus of the Massachusetts Institute of Technology (USA) and exposed to the wet climate of the North-eastern coast of the United States. During nine years of exposition, the wall surface showed an erosion depth comprised between $5 \mathrm{~mm}$ and $7 \mathrm{~mm}$, which corresponds to an annual rate between 0.55 $\mathrm{mm} /$ year and $0.77 \mathrm{~mm} /$ year.

Table 1. Description of main environmental actions affecting the durability of earth buildings.

\begin{tabular}{|c|c|c|c|c|c|c|}
\hline \multirow{2}{*}{$\begin{array}{l}\text { Type of } \\
\text { action }\end{array}$} & \multirow[b]{2}{*}{ Mechanisms of action } & \multicolumn{2}{|c|}{ Vulnerability to action } & \multirow{2}{*}{$\begin{array}{l}\text { Likelihood } \\
\text { of action }\end{array}$} & \multirow{2}{*}{$\begin{array}{l}\text { Speed of } \\
\text { action }\end{array}$} & \multirow{2}{*}{$\begin{array}{l}\text { Overall } \\
\text { impact }\end{array}$} \\
\hline & & $\begin{array}{l}\text { Unstabilised } \\
\text { earth }\end{array}$ & $\begin{array}{l}\text { Stabilised } \\
\text { earth }\end{array}$ & & & \\
\hline Water & $\begin{array}{l}\text { Loss of inter-granular capillary bonds caused by water } \\
\text { infiltration due to rainfall, capillary rise, condensation or } \\
\text { utilities leakage. } \\
\text { Erosion caused by direct rainfall or splash back. } \\
\text { Cracking/spalling caused by repeated swelling-drying } \\
\text { due to wetting-drying cycles. }\end{array}$ & High & $\begin{array}{l}\text { Medium } \\
\text { to } \\
\text { Low } \\
\text { (depend on } \\
\text { type/content } \\
\text { of stabiliser) }\end{array}$ & High & High & High \\
\hline Ice & $\begin{array}{l}\text { Cracking/spalling caused by repeated phase change of } \\
\text { pore water due to freeze-thaw cycles. } \\
\text { Loss of inter-granular chemical bonds caused by } \\
\text { deterioration of stabilisers. }\end{array}$ & Medium & High & $\begin{array}{l}\text { Medium } \\
\text { to } \\
\text { Low }\end{array}$ & High & Medium \\
\hline Fire & $\begin{array}{l}\text { Loss of inter-granular capillary bonds caused by water } \\
\text { evaporation. } \\
\text { Loss of inter-granular chemical bonds caused by } \\
\text { deterioration of stabilisers. } \\
\text { Cracking/spalling caused by shrinkage due to drying. } \\
\text { Cracking/spalling caused by pore vapour pressure } \\
\text { increase. } \\
\text { Loss of hygrothermal inertia due to mineralogical } \\
\text { transformations. }\end{array}$ & $\begin{array}{l}\text { Medium } \\
\text { to } \\
\text { Low }\end{array}$ & $\begin{array}{l}\text { High } \\
\text { to } \\
\text { Medium } \\
\text { (depend on } \\
\text { type/content } \\
\text { of stabiliser) }\end{array}$ & Low & High & Medium \\
\hline Wind & $\begin{array}{l}\text { Erosion caused by air eddies and vortices amplified by } \\
\text { the abrasive effect of suspended particles. }\end{array}$ & Medium & Low & High & Low & Low \\
\hline $\begin{array}{l}\text { Solar } \\
\text { radiation }\end{array}$ & $\begin{array}{l}\text { Loss of inter-granular chemical bonds caused by } \\
\text { deterioration of photosensitive polymeric stabilisers. }\end{array}$ & Low & Medium & High & Low & Low \\
\hline $\begin{array}{l}\text { Chemical } \\
\text { agents }\end{array}$ & $\begin{array}{l}\text { Corrosion of steel reinforcements caused by chlorides or } \\
\text { carbonation. } \\
\text { Loss of inter-granular chemical bonds caused by } \\
\text { deterioration of cement due to sulphates or acidic } \\
\text { environments. } \\
\text { Cracking/spalling caused by swelling due to sulphates or } \\
\text { alkaline environments. }\end{array}$ & Low & $\begin{array}{l}\text { High } \\
\text { to } \\
\text { Medium } \\
\text { (depend on } \\
\text { type/content } \\
\text { of stabiliser } \\
\text { and if earth is } \\
\text { steel } \\
\text { reinforced) }\end{array}$ & $\begin{array}{l}\text { Medium } \\
\text { to } \\
\text { Low }\end{array}$ & Low & Low \\
\hline
\end{tabular}

The difference of erosion rates between [106] and [107] is probably due to dissimilarities between earth materials, construction methods and measurement techniques rather than climate. The climate at the two test sites is in fact rather similar and exhibits an average annual precipitation around $1000 \mathrm{~mm}$ with an average temperature in August little above $20^{\circ} \mathrm{C}$ and an average temperature in January barely above $0^{\circ} \mathrm{C}$, with frost commonly occurring during winter.
The results presented in [106] and [107] are also comparable to earlier estimations of the erosion rate of unstabilised uncoated adobe walls in New Mexico (USA) in [108], which indicated a reduction in thickness of 1 inch over 20 years. This corresponds to an average annual erosion rate of 1.27 $\mathrm{mm} /$ year, which is considerably higher than the rate observed in [106] and [107]. This difference may be possibly explained by the lower density of unstabilised adobe compared to well-compacted rammed earth and/or by the 
relatively severe climatic conditions, characterised by thunderstorms with high winds and large hail, that prevail in some areas of New Mexico.

In summary, the above field studies indicate that the erosion rate of uncoated unstabilised earth walls may be relatively small between $0.32 \mathrm{~mm} /$ year, for well compacted rammed earth, and $1.27 \mathrm{~mm} /$ year, for poorly compacted adobe. Given the slow advancement of the erosive process, the adverse impact of environmental actions on structural durability could be limited by means of a regular maintenance of the building envelope. This conclusion is also supported by some examples of ancient unstabilised earth buildings still in use across the world. The most emblematic example is the UNESCO World Heritage site of Taos Pueblo in New Mexico (USA), which is a complex of adobe houses dating back almost 1000 years ago and still inhabited by about 150 people (Fig. 4). The Taos Pueblo houses are durable enough to have lasted through centuries, though they need regular maintenance to prevent the progressive erosion of the earth structure. This maintenance mainly consists in the application, every year, of a fresh sacrificial layer of mud over the external walls surface.

Field studies provide an accurate estimation of the durability of earth buildings but they are rare due to high financial costs and lengthy execution times. For this reason, laboratory tests have also been developed to measure the durability of earth materials at the scale of small samples.
The majority of tests has been designed to measure the durability of earthen materials to water. In this category, three main families of experimental procedures can be identified. The first family, which is described in the Australian earth building handbook (HB 195) [109], assesses the resistance of the material to the erosion caused by water impact and includes the accelerated erosion test, the geelong drip test and the Swinburne erosion test. Another test that could be included in this family is the wearing test described in the American standard ASTM D559-03 [110], even if in this case erosion is not induced by the impact of water but rather by the stroke of a wire brush. The second family of experimental procedures assesses instead the resistance of the material to the exposure to excess water and includes: a) the wet-dry appraisal test described in the Australian earth building handbook (HB 195) [109], b) the contact test, suction test and dip test described in the German standard DIN $18945: 2013$ [111] and c) the swelling/shrinkage test described in the French standard XP-P13-901 [70]. The last family assesses the occurrence of material collapse caused by wetting and includes uniaxial and confined compression tests on soaked specimens. For all the above tests, however, no clear correlation has so far been made between laboratory test results and the in-situ durability of the material [109].

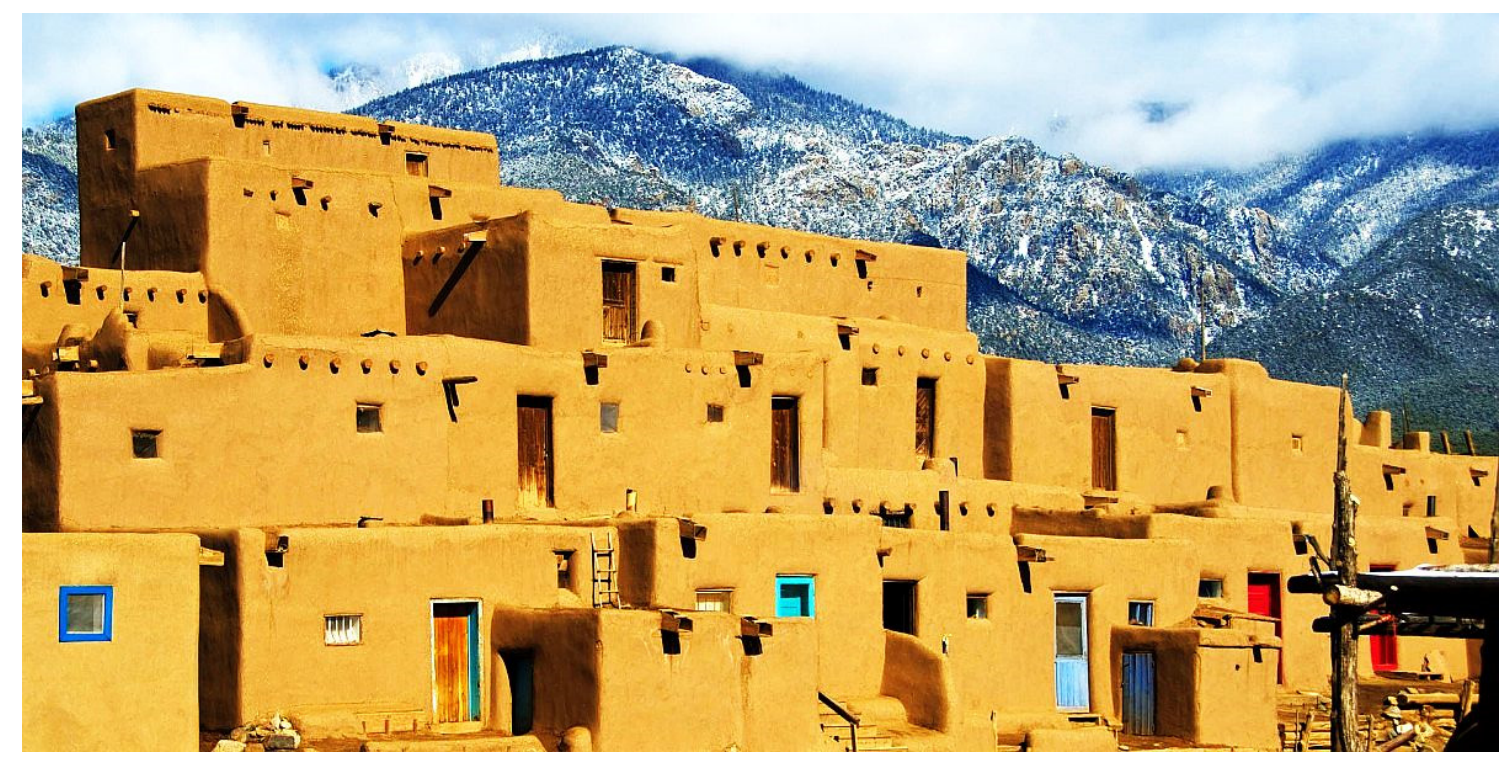

Figure 4. Ancient unstabilised adobe dwellings inhabited by a native American tribe of about 150 people at Taos Pueblo in New Mexico (USA).

Different tests have also been proposed to investigate the durability of earth materials to other environmental actions. This proliferation of empirical procedures has however complicated the formulation of testing standards which can be embraced by construction practitioners and building authorities worldwide. A possible way to overcome this limitation may consist in replacing the current plethora of experimental protocols with a single standardised durability test, such as for example an abrasion/erosion test, which could be used regardless of the particular environmental action under consideration. The specific effect of each environmental action could then be taken into account by subjecting the samples to distinct accelerated ageing processes (corresponding to the different actions listed in Table 1) before being tested. The choice of the test would therefore be separated from the choice of the environmental action, which would simplify empirical procedures and 
facilitate the formulation of internationally accepted experimental protocols.

\section{Concluding remarks}

This paper has emphasized the lack of standard experimental protocols for assessing the engineering performance of earth materials and the associated difficulties in selecting design parameters. An illustrative example is provided by the measurement of dry mass, for which no consensus exists yet despite the importance of this parameter for determining key material characteristics such as adsorption-desorption capacity, dry density, thermal conductivity, heat capacity, strength and stiffness. Similarly, different laboratory protocols exist for the determination of moisture conductivity, moisture buffering capacity and water durability, which complicates comparison between measurements.

Laboratory procedures may also not be representative of field conditions. The relative homogeneity of laboratory samples may not reflect field conditions and test procedures may be very different from the actions experienced by buildings during service life [112]. An illustrative example is given by the measurement of the unconfined compressive strength, which is commonly determined on samples with densities and water contents that are unrepresentative of field conditions. Similarly, water erosion tests appear too severe and can be hardly used to discriminate between earth materials [113]. The irrelevance of current experimental protocols to field conditions is partly the consequence of the scarcity of studies at the building scale. These studies, if available, would help understanding the mechanism through which external actions affect buildings and would therefore allow the development of accurate laboratory procedures. Moreover, whenever field data are available, it remains difficult to draw sound conclusions, mainly because of the lack of accurate monitoring of environmental actions.

On a more positive note, consensus is starting to emerge about the experimental procedures of some categories of laboratory tests. For example, it is now acknowledged that the measurement of vapour diffusion should take into account the film moisture resistance at the sample surface and that the determination of moisture buffering capacity must follow standard wetting-drying protocols that limit damages to the material. It seems as well possible to achieve consensus about the procedures for measuring strength or stiffness and about the importance of controlling temperature and humidity during mechanical tests on unstabilized earth. Conversely, laboratory procedures for the measurement of the tensile and shear strength of earth materials are still being developed and it is not possible at this stage to draw conclusions about the suitability of protocols.

Finally, with reference to the measurement of durability, distinct experimental procedures have been proposed for different environmental actions (e.g. the actions of water, frost, fire, wind), which has led to a large number of testing protocols and a consequent lack of standardisation. This difficulty might be overcome by abandoning the unique correspondence between testing protocols and type of action, so that a single experiment might be used to characterise the durability of earth samples exposed to different environmental agents. In this respect, however, the development of accelerated ageing procedures, which can replicate in the laboratory the protracted action of environmental agents in the field, remains a challenge. Among the different environmental agents, water is the most detrimental one to durability. This is particularly true for unstabilized earth, though the recent development of unconventional binders may give rise in the future to durability issues also for stabilised earth.

\section{Acknowledgment}

This work was realized in the framework of the RILEM technical committee TCE 274. The authors would like to acknowledge all the active members of this TC.

\section{References}

[1] J. C. Morel, A. Mesbah, M. Oggero, P. Walker, Building houses with local materials: means to drastically reduce the environmental impact of construction. Build Environ (2011) 36 (10): 1119-1126. https://doi.org/10.1016/S0360-1323(00)00054-8

[2] G. Habert, E. Castillo, E. Vincens, J. Morel, Power: A new paradigm for energy use in sustainable construction. Ecol Indic (2012) 23: 109-115. https://doi.org/10.1016/j.ecolind.2012.03.016

[3] M. R. Hall, R. Lindsay, M. Krayenhoff, Modern earth buildings. Woodhead, 2012. https://doi.org/10.1533/9780857096166

[4] H. Van Damme, Colloidal Chemo-Mechanics of Cement Hydrates and Smectite Clays: Cohesion vs Swelling. Taylor \& Francis Group, London, 2006.

[5] X. Lei, H. Wong, A. Fabbri, A. Limam, Y. M. Cheng, A chemo-elasticplastic model for unsaturated expansive clays. Int J Solids Struct (2016) 88-89: 354-378. https://doi.org/10.1016/i.ijsolstr.2016.01.008

[6] P. Walker, Strength, durability and shrinkage characteristics of cement stabilised soil blocks. Cem Concr Compos (1995) 17 (4): $301-$ 310. https://doi.org/10.1016/0958-9465(95)00019-9

[7] D. Maskell, A. Heath, P. Walker, Inorganic stabilisation methods for extruded earth masonry units. Constr Build Mater (2014) 71: 602609. https://doi.org/10.1016/i.conbuildmat.2014.08.094

[8] Y. Millogo, J. E. Aubert, A. D. Séré, A. Fabbri, J. C. Morel, Microstructural characterization and mechanical properties of cement stabilised adobes. Earth blocks Stab by cow-dung (2016) 49: 4583-4594.

[9] N. Cristelo, S. Glendinning, T. Miranda, D. Oliveira, R. Silva, Soil stabilisation using alkaline activation of fly ash for self compacting rammed earth construction. Constr Build Mater (2012) 36: 727-735. https://doi.org/10.1016/j.conbuildmat.2012.06.037

[10] J. W. Garrison, E. F. Ruffner, Adobe: Pratical and technical aspects of adobe conservations. J Ariz Hist (1983): 448-501.

[11] J. E. Aubert, A. Marcom, P. Oliva, P. Segui, Chequered earth construction in south-western France. J Cult Herit (2015) 16: 293298. https://doi.org/10.1016/j.culher.2014.07.002

[12] M. I. Gomes, T. D. Gonçalves, P. Faria, Unstabilised rammed earth: characterization of material collected from old constructions in South Portugal and comparison to normative requirements. Int J Archit Herit (2014) 8: 185-212. https://doi.org/10.1080/15583058.2012.683133

[13] F. Champiré, A. Fabbri, J. Morel, H. Wong, F. Mcgregor, Impact of relative humidity on the mechanical behavior of compacted earth as a building material. Constr Build Mater (2016) 110: 70-78. https://doi.org/10.1016/j.conbuildmat.2016.01.027

[14] H. Janssen, B. Blocken, J. Carmeliet, Conservative modelling of the moisture and heat transfer in building components under atmospheric excitation. Int J Heat Mass Transf (2007) 50 (5-6): 11281140. https://doi.org/10.1016/j.ijheatmasstransfer.2006.06.048

[15] L. Soudani, A. Fabbri, J.-C. Morel, M. Woloszyn, P.-A. Chabriac, A.-C. Grillet, Assessment of the validity of some common assumptions in 
hygrothermal modeling of earth based materials. Energy Build (2016) 116: 498-511. https://doi.org/10.1016/j.enbuild.2016.01.025

[16] P. Arnold, Thermal conductivity of masonry materials. J Inst Heat Vent Eng (1969) 37: 101-108.

[17] J. Laurent, Contribution à la caractérisation thermique des milieux poreux granulaires. Institut National Polytechnique, Grenoble, 1986.

[18] CSTB, Analyse des caractéristiques des systèmes constructifs non industrialisés, 2011.

[19] P. A. Chabriac, Mesure du comportement hygrothermique du pisé, ENTPE, 2014.

[20] F. Volhard, Leichtlehmbau: alter Baustoff - neue Technik. Karlsruhe, 1983.

[21] E. A. Adam, P. J. Jones, Thermophysical properties of stabilised soil building blocks. Build Environ (1995) 30 (2): 245-253. https://doi.org/10.1016/0360-1323(94)00041-P

[22] E. A. Adam, Compressed Stabilized earth Block Manufacturing in Sudan - UNESCO - Technical Note No. 12. Organization (2001): 101.

[23] P. Walker, R. Keable, J. Martin, V. Maniatidis, Rammed Earth: Design and construction guidelines, in Innovation Project: "Developing Rammed Earth for UK Housing.," 2004.

[24] P. Taylor, R. J. Fuller, M. B. Luther, Energy use and thermal comfort in a rammed earth office building. Energy Build (2008) 40: 793-800. https://doi.org/10.1016/i.enbuild.2007.05.013

[25] M. R. Hall, D. Allinson, Assessing the effects of soil grading on the moisture contentdependent thermal conductivity of stabilised rammed earth materials. Appl Therm Eng (2009) 29: 740-747. https://doi.org/10.1016/j.applthermaleng.2008.03.051

[26] D. Allinson, M. Hall, Hygrothermal analysis of a stabilised rammed earth test building in the UK. Energy Build (2010). https://doi.org/10.1016/j.enbuild.2009.12.005

[27] J. E. Oti, J. M. Kinuthia, J. Bai, Design thermal values for unfired clay bricks. Mater Des (2010) 31: 104-112. https://doi.org/10.1016/j.matdes.2009.07.011

[28] ISO-8302, Thermal insulation -Determination of steady-state thermal resistance and related properties - Guarded hot plate apparatus. International Organization for Standardization, 1991.

[29] ASTM-C177, Standard Test Method for Steady-State Heat Flux Measurements and Thermal Transmission Properties by Means of the Guarded-Hot-Plate Apparatus. ASTM International, 2013.

[30] DIN-52612-2, Tesing of thermal insulating materials; determination of thermal conductivity by means of the guarded hot plate apparatus; conversion of the measured values for building applications. Deutsches Institut für Normung, 1984.

[31] ASTM-D5334, Standard Test Method for Determination of Thermal Conductivity of Soil and Soft Rock by Thermal Needle Probe Procedure. ASTM International, 2014.

[32] IEEE-442, IEEE Guide for soil thermal resistivity measurements. Institute of Electrical and Electronics Engineers, 1981.

[33] ISO-22007-2, Determination of thermal conductivity and thermal diffusivity -- Part 2: Transient plane heat source (hot disc) method. International Organization for Standardization. 2015.

[34] ISO-11357-1, Plastics - Differential scanning calorimetry (DSC) -- Part 1: General principles. International Organization for Standardization. 2016.

[35] ASTM-E793-06, Standard Test Method for Enthalpies of Fusion and Crystallization by Differential Scanning Calorimetry. ASTM International. 2012.

[36] DIN-51007, Thermal analysis; differential thermal analysis; principles. Deutsches Institut für Normung, 1994.

[37] F. McGregor, A. Fabbri, J. Ferreira, T. Simões, P. Faria, J. C. Morel, Procedure to determine the impact of the surface film resistance on the hygric properties of clay plasters. Mater Struct (2017) 50:193. https://doi.org/10.1617/s11527-017-1061-3

[38] K. Svennberg, Moisture buffering in the indoor environment, LTH, Lund University, 2006.

[39] C. Feng, H. Janssen, Y. Feng, Q. Meng, Hygric properties of porous building materials: Analysis of measurement repeatability and reproducibility. Build Environ (2015) 85: 160-172. https://doi.org/10.1016/i.buildenv.2014.11.036

[40] O. Vololonirina, B. Perrin, Inquiries into the measurement of vapour permeability of permeable materials. Constr Build Mater (2016) 102: 338-348. https://doi.org/10.1016/j.conbuildmat.2015.10.126

[41] J. P. Rodrigues Ferreira, Influence of temperature on the sorptiondesorption curves of earth-based materials and consequences on their hygrothermal behaviour, Master thesis of the Universidade NOVA de Lisboa, 2016.
[42] Y. A. Oumeziane, S. Moissette, M. Bart, C. Lanos, Influence of temperature on sorption process in hemp concrete. Constr Build Mater (2016) 106: 600-607. https://doi.org/10.1016/j.conbuildmat.2015.12.117

[43] C. Feng, H. Janssen, Hygric properties of porous building materials (II): Analysis of temperature influence. Build Environ (2016) 99: 107-118. https://doi.org/10.1016/j.buildenv.2016.01.016

[44] V. Baroghel-Bouny, M. Thiery, F. Barberon, G. Villain, Assessment of transport properties of cementitious materials: a major challenge as regards durability? Eur J Environ Civ Eng (2007) 11 (6): 671-696.

[45] M. Hall, Y. Djerbib, Moisture ingress in rammed earth: Part 1- the effect of soil particle-size distribution on the rate of capillary suction. Constr Build Mater (2004) 18 (4): 269-280. https://doi.org/10.1016/j.conbuildmat.2003.11.002

[46] P.-A. Chabriac, Mesure du comportement hygrothermique du pisé, ENTPE, Université de Lyon, France, 2014.

[47] M. Krus, A. Holm, Simple method to approximate the liquid Transport coefficient describing the absorption and drying, in 5th symposium Building Physics in the Nordic Countries - Göteborg, August 24-261, (1999): 241-248.

[48] M. Raimondo, M. Dondi, D. Gardini, G. Guarini, F. Mazzanti, Predicting the initial rate of water absorption in clay bricks. Constr Build Mater (2009) 23 (7): 2623-2630. https://doi.org/10.1016/j.conbuildmat.2009.01.009

[49] I. Gomes, T. D. Gonçalves, P. Faria, Hygric Behavior of Earth Materials and the Effects of their Stabilization with Cement or Lime: Study on Repair Mortars for Historical Rammed Earth Structures. J Mater Civ Eng (2016) 28 (7): 04016041. https://doi.org/10.1061/(ASCE)MT.1943-5533.0001536

[50] H. M. Kunzel, Simultaneous heat and moisture transport in building components one - and two-dimensional calculation using simple parameters - Report on PhD thesis, Fraunhofer Institute of Building Physics, 1995.

[51] F. Rouquerol, J. Rouquerol, K. Sing, Adsorption by powders and porous solids. Elsevier, 1999.

[52] A. Fabbri, F. McGregor, I. Costa, P. Faria, Effect of temperature on the sorption curves of earthen materials. Mater Struct Constr (2017) 50 (6): 253. https://doi.org/10.1617/s11527-017-1122-7

[53] A. Fabbri, F. McGregor, Impact of the determination of the sorptiondesorption curves on the prediction of the hemp concrete hygrothermal behaviour. Constr Build Mater (2017) 157: 108-116. https://doi.org/10.1016/i.conbuildmat.2017.09.077

[54] D. Lelievre, T. Colinart, P. Glouannec, Hygrothermal behavior of biobased building materials including hysteresis effects: Experimental and numerical analyses. Energy Build (2014) 84: 617-627. https://doi.org/10.1016/i.enbuild.2014.09.013

[55] C. Rode et al., Nordic Innovation Centre: Moisture Buffer Value of Building Materials, Tech Rep Tech Univ Denmark, 2005.

[56] P. Faria, A. Bras, Building physics, in Performance of Bio-based Building Materials, D. Jones and C. Brischke, Eds. Woodhead Publishing Series in Civil and Structural Engineering, (2017): 335-344.

[57] F. McGregor, A. Heath, D. Maskell, A. Fabbri, J.-C. J.-C. Morel, A review on the buffering capacity of earth building materials, Proceedings of the Institution of Civil Engineers - Construction Materials (2016) 169 (5): 241-251. https://doi.org/10.1680/jcoma.15.00035

[58] S. Kunkel, E. Kontonasiou, A. Arcipowska, F. Mariottini, B. Atanasiu, Analysis of residential building regulations in eight EU members states - BPIE report, 2015.

[59] Q. Bui, J. Morel, S. Hans, P. Walker, Effect of moisture content on the mechanical characteristics of rammed earth. Constr Build Mater (2014) 54: 163-169. https://doi.org/10.1016/j.conbuildmat.2013.12.067

[60] J. C. Morel, A. Pkla, P. Walker, Compressive strength testing of compressed earth blocks. Constr Build Mater (2007) 21 (2): 303-309. https://doi.org/10.1016/j.conbuildmat.2005.08.021

[61] L. Miccoli, U. Müller, P. Fontana, Mechanical behaviour of earthen materials: A comparison between earth block masonry, rammed earth and cob. Constr Build Mater (2014) 61: 327-339. https://doi.org/10.1016/j.conbuildmat.2014.03.009

[62] P. A. Jaquin, C. E. Augarde, D. Gallipoli, D. G. Toll, The strength of unstabilised rammed earth materials. Géotechnique (2009) 59: 487490. https://doi.org/10.1680/geot.2007.00129

[63] J.-E. Aubert, A. Fabbri, J.-C. Morel, P. Maillard, An earth block with a compressive strength higher than $45 \mathrm{MPa}$ ?. Constr Build Mater (2013) 47: 366-369. https://doi.org/10.1016/i.conbuildmat.2013.05.068 
[64] J. E. Aubert, P. Maillard, J. C. Morel, M. Al Rafii, Towards a simple compressive strength test for earth bricks?. Mater Struct (2016) 49 (1): 1641-1654. https://doi.org/10.1617/s11527-015-0601-y

[65] M. Olivier, A. Mesbah, Le Matériau Terre: Essai de Compactage Statique Pour La Fabrication de Briques de Terre Compressées, Bull. Liaison du Lab. Cent. des Ponts Chaussées, vol. 146, 1986.

[66] J.-C. Morel, A. Pkla, P. Walker, Compressive Strength Testing of Compressed Earth Blocks. Constr Build Mater (2007) 21: 303-309. https://doi.org/10.1016/j.conbuildmat.2005.08.021

[67] C.-H. Kouakou, J.-C. Morel, Strength and Elasto-Plastic Properties of Nonlndustrial Building Materials Manufactured with Clay as a Natural Binder. Appl Clay Sci (2009)44: 27-34. https://doi.org/10.1016/i.clay.2008.12.019

[68] M. Olivier, Le matériau terre, compactage, comportement, application aux structures en bloc sur terre, INSA de Lyon, ENTPE, 1994.

[69] J. E. Aubert, A. Fabbri, J. C. Morel, P. Maillard, An earth block with a compressive strength higher than $45 \mathrm{MPa}$ !. Constr Build Mater (2013) 47: 366-369. https://doi.org/10.1016/j.conbuildmat.2013.05.068

[70] AFNOR, XP-P-13-901 French standard: Blocs de terre comprimée pour murs et cloisons. 2001.

[71] J. C. Morel, A. P'kla, H. Di Benedetto, Essai in situ sur blocs de terre comprimée. Rev Française Génie Civ (2003) 7: 221-237. https://doi.org/10.1080/12795119.2003.9692490

[72] M. Olivier, A. Mesbah, Constitutive-Equations for Compacted Soils (In French), in Unsaturated Soils. Proc. 1st Int. Conf. on Unsaturated Soils (UNSAT 95), (1995): 765-773.

[73] W. Riyono, E. Vincens, J. Plassiard, A hierarchical constitutive model for rammed earth. Constr Build Mater (2018) 160: 351-364. https://doi.org/10.1016/j.conbuildmat.2017.11.061

[74] L. Xu, H. Wong, A. Fabbri, F. Champiré, D. Branque, Modelling the poroplastic damageable behaviour of earthen materials. Mater Struct Constr (2018) 51 (4): 112. https://doi.org/10.1617/s11527-018-1229-5

[75] J. S. J. Cheah, P. Walker, A. Heath, T. K. K. B. Morgan, Evaluating shear test methods for stabilised rammed earth. Proc Inst Civ Eng Constr Mater (2012) 165: 325-334. https://doi.org/10.1680/coma.10.00061

[76] K. Liu, M. Wang, Y. Wang, Seismic retrofitting of rural rammed earth buildings using externally bonded fibers. Constr Build Mater (2015) 100: 91-101. https://doi.org/10.1016/i.conbuildmat.2015.09.048

[77] R. El-Nabouch, Q.-B. Bui, O. Plé, P. Perrotin, Assessing the in-plane seismic performance of rammed earth walls byusing horizontal loading tests. Eng Struct (2017) 145: 153-161. https://doi.org/10.1016/i.engstruct.2017.05.027

[78] L. Miccoli, D. V. Oliveira, R. A. Silva, U. Müller, L. Schueremans, Static behaviour of rammed earth : experimental testing and finite element modelling. Mater Struct (2015): 3443-3456. https://doi.org/10.1617/s11527-014-0411-7

[79] R. Silva, D. Olliveira, L. Schueremans, T. Miranda, J. Machado, Shear behaviour of rammed earth walls repaired by means of grouting. in 9th International Masonry Conference, (2014): 1-12.

[80] R. El-Nabouch, Q.-B. Bui, O. Plé, P. Perrotin, Characterizing the shear parameters of rammed earth material by using a full-scale direct share box. Constr Build Mater (2018) 171: 414-420. https://doi.org/10.1016/j.conbuildmat.2018.03.142

[81] A. Corbin, C. Augarde, Investigation into the shear behaviour of rammed earth using shear box tests. First International Conference On Bio-based Building Materials (2015): 93-98.

[82] H. Araki, J. Koseki, T. Sato, Tensile strength of compacted rammed earth materials. Soils Found (2016) 56 (2): 189-204. https://doi.org/10.1016/j.sandf.2016.02.003

[83] P. Gerard, M. Mahdad, A. Robert McCormack, B. François, A unified failure criterion for unstabilized rammed earth materials upon varying relative humidity conditions. Constr Build Mater (2015) 95: 437-447. https://doi.org/10.1016/j.conbuildmat.2015.07.100

[84] E. Araldi, E. Vincens, A. Fabbri, J.-P. Plassiard, Identification of the mechanical behaviour of rammed earth including water content influence. Mater Struct (2018) 51(4): 88. https://doi.org/10.1617/s11527-018-1203-2

[85] L. Xu, K. K. Wong, A. Fabbri, F. Champiré, D. Branque, Loadingunloading shear behavior of rammed earth upon varying clay content and relative humidity conditions. Soils Found, 2018.

[86] B. V. Venkatarama Reddy, C. Vyas, Influence of shear bond strength on compressive strength and stress-strain characteristics of masonry. Mater Struct (2008) 41: 1697-1712. https://doi.org/10.1617/s11527-008-9358-x
[87] K. Venu Madhava Rao, B. V. Venkatarama Reddy, K. S. Jagadish, Flexural bond strength of masonry using various bricks and mortars. Mater Struct (1996) 29: 119-124. https://doi.org/10.1007/BF02486202

[88] P. Walker, Bond characteristics of earth bocks masonry. J Mater Civ Eng (1999): 249-256. https://doi.org/10.1061/(ASCE)0899-1561(1999)11:3(249)

[89] T. T. Bui, Q. B. Bui, A. Limam, S. Maximilien, Failure of rammed earth walls: From observations to quantifications. Constr Build Mater (2014) 51: 295-302. https://doi.org/10.1016/i.conbuildmat.2013.10.053

[90] A. Tennant, C. Foster, B. V. Venkatarama Reddy, Detailed experimental review of flexural behavior of cement stabilized soil block masonry. J Mater Civ Eng (2016) 28. https://doi.org/10.1061/(ASCE)MT.1943-5533.0001548

[91] B. V. Venkatarama Reddy, A. Gupta, Tensile bond strength of soilcement block masonry couplets using cement-soil mortars. J Mater Civ Eng (2006) 18: 36-45. https://doi.org/10.1061/(ASCE)0899-1561(2006)18:1(36)

[92] P. Scarato, J. Jeannet, Cahier d'expert bâti en pisé: Connaissance, analyse, traitement des pathologies du bâti en pisé en Rhône-Alpes et Auvergne. 2015.

[93] A. W. Bruno, D. Gallipoli, C. Perlot, J. Mendes, Effect of stabilisation on mechanical properties, moisture buffering and water durability of hypercompacted earth. Constr Build Mater (2017): 733-740.

[94] R. Eires, A. Camões, S. Jalali, Earth architecture: ancient and new methods for durability improvement, in Structures and Architecture: New concepts, applications and challenges, P. J. da Sousa Cruz, Ed. CRC Press, (2013): 962-970. https://doi.org/10.1201/b15267-135

[95] A. W. Bruno, D. Gallipoli, C. Perlot, J. Mendes, Mechanical behaviour of hypercompacted earth for building construction. Mater Struct (2017) 50 (2): 160. https://doi.org/10.1617/s11527-017-1027-5

[96] G. Minke, Building with earth: design and technology of a sustainable architecture. Birkhäuser - Publishers for Architecture, 2012.

[97] J. E. Aubert, M. Gasc-Barbier, Hardening of clayey soil blocks during freezing and thawing cycles. Appl Clay Sci (2012)65: 1-5. https://doi.org/10.1016/j.clay.2012.04.014

[98] A. Guettala, A. Abibsi, H. Hourari, Durability study of stabilized earth concrete under both laboratory and climatic conditions exposure. Constr Build Mater (2006) 20: 119-127. https://doi.org/10.1016/i.conbuildmat.2005.02.001

[99] H. Schroeder, Sustainable building with earth. Springer, 2016. https://doi.org/10.1007/978-3-319-19491-2

[100] E. Obonyo, J. Exelbirt, M. Baskaran, Durability of compressed earth bricks: assessing erosion resistance using the modified spray testing. Sustainability (2010) 2: 3639-3649. https://doi.org/10.3390/su2123639

[101] W. S. Chepil, N. P. Woodruff, The physics of wind erosion and its control. Adv Agron (1963) 15: 211-302. https://doi.org/10.1016/S0065-2113(08)60400-9

[102] L. Lian-You, G. Shang-Yu, S. Pei-Jun, L. Xiao-Yan, D. Zhi-Bao, Wind tunnel measurements of adobe abrasion by blown sand: profile characteristics in relation to wind velocity and sand flux. J Arid Environ (2003) 53: 351-363. https://doi.org/10.1006/jare.2002.1049

[103] A. L. Andrady, S. H. Hamid, X. Hu, A. Torikai, Effects of increased solar ultraviolet radiation on materials. J Photochem Photobiol B Biol (1998) 46: 96-103. https://doi.org/10.1016/S1011-1344(98)00188-2

[104] M. J. Melo, S. Bracci, M. Camaiti, O. Chiantore, F. Piacenti, Photodegradation of acrylic resins used in the conservation of stone. Polym Degrad Stab (1999) 66: 23-30. https://doi.org/10.1016/S0141-3910(99)00048-8

[105] N. Degirmenci, B. Baradan, Chemical resistance of pozzolanic plaster for earthen walls. Constr Build Mater (2005) 19: 536-542. https://doi.org/10.1016/j.conbuildmat.2004.12.002

[106] Q. B. Bui, J. C. Morel, B. V. Venkatarama Reddy, W. Ghayad, Durability of rammed earth walls exposed for 20 years to natural weathering. Build Environ (2009) 44: 912-919. https://doi.org/10.1016/i.buildenv.2008.07.001

[107] A. J. Dahmen, Who's afraid of raw earth? Experimental wall in New England and the environmental. Proceedings of the First International Conference on Rammed Earth Construction (ICREC2015) (2015): 85-88. https://doi.org/10.1201/b18046-17

[108] H. Özen, Residential adobe architecture around Santa Fe and Taos from 1900 to the present, Texas Tech University, 1990. 
[109] P. Walker, The Australian earth building handbook HB195. Standards Austrialia, 2002

[110] ASTM-D559-03, Standard Test Methods for Wetting and Drying Compacted Soil-Cement Mixtures. American Society for Testing and Materials International, 2012.

[111] DIN-18945, Earth blocks - terms and definitions, requirements, test methods. 2012.

[112] L. Soudani, A. Fabbri, F. McGregor, J.-C. Morel, Laboratory investigation of hygrothermal monitoring of hemp-concrete walls. RILEM Tech Lett (2017) 2: 20. https://doi.org/10.21809/rilemtechlett.2017.36

[113] I. Kharoti, P. Walker, C. Jayasinghe, Durability of rammed earth: a comparative study of spary erosion testing and natural weathering. International Symposium on Earthen Structures (ISES-2018) (2018): 79. 